\title{
Vector space representation of array antenna pattern synthesis problems
}

\author{
Wu, Jian; Roederer, A.G
}

Published in:

Antennas and Propagation Society International Symposium

Link to article, DOI:

10.1109/APS.1991.175184

Publication date:

1991

Document Version

Publisher's PDF, also known as Version of record

Link back to DTU Orbit

Citation (APA):

Wu, J., \& Roederer, A. G. (1991). Vector space representation of array antenna pattern synthesis problems. In Antennas and Propagation Society International Symposium (Vol. Volume 3, pp. 1700-1703). IEEE. https://doi.org/10.1109/APS.1991.175184

\section{General rights}

Copyright and moral rights for the publications made accessible in the public portal are retained by the authors and/or other copyright owners and it is a condition of accessing publications that users recognise and abide by the legal requirements associated with these rights.

- Users may download and print one copy of any publication from the public portal for the purpose of private study or research.

- You may not further distribute the material or use it for any profit-making activity or commercial gain

- You may freely distribute the URL identifying the publication in the public portal

If you believe that this document breaches copyright please contact us providing details, and we will remove access to the work immediately and investigate your claim 
VECTOR SPACE REPRESENTATION OF ARRAY ANTENNA PATTERN SINTHESIS PROBLEMS

\author{
$\mathrm{Ji} \mathrm{Wu+}{ }^{*}$, A. G. Roederer++ \\ +Technical University of Denmark \\ Building 348, EMI, DK-2800, Lyngby, Denmark \\ ++ESA/ESTEC, Postbus 299, 2200 AG, Noordwijk \\ The Netherlands
}

\begin{abstract}
Considering the difficulties of the non-linear optimization methods for the array and array fed reflector antenna power pattern synthesis problems, a novel approach has been developed to present the problem in a geographical way, which allows to derive efficient algorithms and to visualise the optimization process.
\end{abstract}

\title{
Introduction
}

Although many computational methods for array or array fed reflector pattern synthesis have been developed, some difficulties are still present with regard to main beam shaping, sidelobe suppression, cross-polar isolation, wide-band design, beam efficiency, non-super-gain solutions, local optimum solutions, etc. The main reason is probably that the synthesis problem is difficult to represent in a clear and general way which may cover all the problems mentioned above. This paper is devoted to the derivation of a vectorial representation of the problem, a separate paper [1] will deal with the optimization algorithm.

\section{Vector Space Representation}

In the case of fixed array or multifeed reflector configuration where only the element excitations (not their positions) can be adjusted, the synthesis procedure can be separated from the analysis [2][3]. The field in a far field sampling direction $j$ is

$$
E_{j}=\left\langle e_{j}, a^{*}>=\sum_{j=1}^{n} e_{j i} a_{i} \quad(j=1, m)\right.
$$

where $\mathrm{m}$ is the number of far field sampling directions and $\mathrm{n}$ is the number of elements. $e_{j}(j=1, m)$ are the field vectors in $n$-dimensional Hilbert space. They characterise the radiation system and is obtained by the analysis procedure. Once the array structure is fixed, $e_{j}$ 's are fixed. $\mathbf{a}$ is the complex excitation vector. The synthesis problem is then to find the best excitation vector $\mathbf{a}$ according to a certain pattern specification.

In most applications, only the field magnitude (or power) pattern is of interest. The following discussion will concentrate on this kind of

91CH3036-1/0000-1700\$1.00 @1991 IEEE 
application only. From equation (1), the field magnitude can be expressed as:

$$
\begin{aligned}
\left|E_{j}\right|= & <F_{j}, a^{*}>\quad(j=1, m) \\
F_{j} & \left.=\mathbf{e}_{j}<\mathbf{e}_{j}, \mathbf{a}^{*}\right\rangle^{*} / I<\mathbf{e}_{j}, \mathbf{a}^{*}>1 .
\end{aligned}
$$

where

The right hand side of (2) is similar to that of (1) but the field vector $e_{j}$ is replaced by a new vector $F_{j}$ defined in (3) which has the same norm as $\mathbf{e}_{j}$ with a rotation related to the current direction of $\mathbf{a}$. In the following discussion, $\mathbf{F}_{\mathbf{j}}$ will be called field vector still.

\section{Representation of the General Synthesis Problem}

Equation (2) shows that the field magnitude is an inner productor between two vectors. If $a$ is normalized for unit total input power, the projection length of $F_{j}$ on a represents the field magnitude $|E j|$. The synthesis problem is then to find the direction of the excitation vector a to get the right projection lengths from $F_{j}$ s $(j=1, m)$ weighted according to the specified pattern function. If the inner productor is real, the Euclidean angle $\Phi j$ between the two vectors $F_{j}$ and $a^{*}$ is given by:

$$
\cos \Phi \mathrm{j}=\left\langle\mathbf{F j}, \mathbf{a}^{*}>/(|| \mathbf{F j}|||| \mathbf{a}||) .\right.
$$

The problem can be represented graphically now. Fig.1 shows a simple case where three field vectors sampled from the main beam direction are $F_{1}, F_{2}$ and $F_{3}$. The projection lengths on a must be optimized to be equal (different main beam shape will be discussed later). The dashed vectors represent an initial situation where $a$ is not in an optimum direction because the projection length from $F_{1}$ is very small. The solid vectors represent the best solution of this case where $\left|E_{1}\right|,\left|E_{2}\right|$ and $\left|E_{3}\right|$ are equal.

\section{Necessary condition of the optimum solution}

Based on the above representation the necessary condition of an optimum solution is given as the follows: An optimum excitation vector a must be normal to the super plane which is defined by the extremities of active field vectors. In the corresponding directions, the field magnitudes are then equal or weighted as required.

Sufficient Condition For Global Optimum Solution

The above condition will give a solution where the shape of tlee pattern agrees with the desired one but the gain of the antenna may not be maximized. Since the field vector $F_{j}$ is rotating while the excitation vector $a$ is changing direction, the super plane defined by a set of active field vectors is also changing. As mentioned above, at an optimum solution, the projections of all the active field vectors on a will be at the same point, that is the intersection point of a (or the extension of $\mathbf{a}$, if $\mathbf{a}$ is normalized) and the super plane, see Fig.2. The 
distance between this point and the origin is also the distance between the super plane and the origin since $a$ is in the normal direction to the plane. Therefore the sufficient and also the necessary condition of the global optimum solution is: The global optimum excitation vector $\mathbf{a}$ is in the direction of the normal to the super plane (as defined above) which has the biggest distance from the origin.

The sufficient condition of the global optimum solution reflects the non-linearity of the problem. One method may equalize the field magnitudes at all the sampling directions, which means the synthesized pattern has the exact value as the desired one at those directions, but it may not yield the best gain performance.

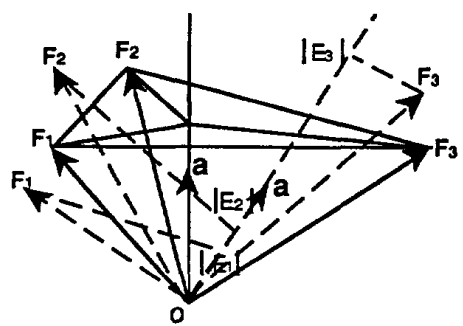

Fig. 1

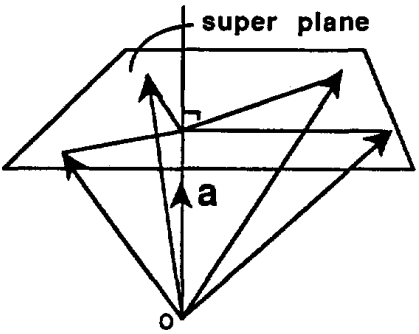

Fig.2

Representation of Different Synthesis Parameters 1. Beam shaping: Different desired pattern values will be used to weigh the corresponding field vector's norms. The extremities of active field vectors which define the super plane will have the exact specified value after the optimization. The rest (if there is any) will be above the plane on the other side respect to the origin according to a maximin design concept [4][5], see Fig.3, or equally distributed on both sides of the plane according to the minimax design concept[3][6].

un-active

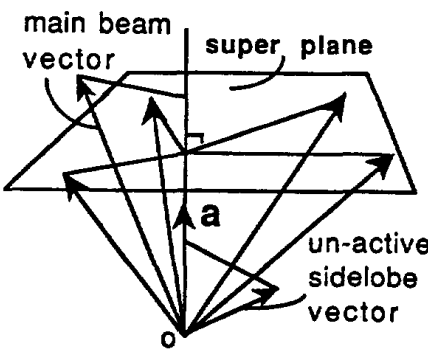

Fig.3
2. Sidelobe suppression: Wanted sidelobe levels will be used to weigh the corresponding sidelobe region field vector's norms. Their extremities will be either in the super plane or below, on the same side as the origin, see Fig.3. 3. Cross-polar suppression: Field vectors can be calculated at the far-field sampling directions where cross-polar level are specified. Those cross-polar field vectors will be treated as the sidelobe region field vectors. 
4. Wide-band design: Different field vectors have to be calculated at different frequencies in the band. The number of vectors will be multiplied by the number of frequencies.

5. Main beam efficiency and non-super-gain solution: Those two aspects will be fulfilled automatically by optimizing directly the field value of equation (2) instead of an error function or the directivity of the array.

\section{Conclusions}

The vector space approach is very powerful to represent the array pattern synthesis problems. It is not only general since many parameters are represented under one model, but also helps to visualize the problem. The proposed approach also provides a new support for optimization algorithms. Related developments will be found in a separate paper.

\section{References}

[1] J. Wu and Roederer, "Maximin super angle optimization method for array antenna pattern synthesis", to be presented at AP-S Symposium, London, Canada, June 1991

[2] J.R. Mautz and R.F. Harrington, "Computational methods for antenna pattern synthesis", IEEE Tran., AP-23, pp.507.512, July 1975

[3] H.S. Jacobsen and K. Madsen, "Synthesis of nonuniformly spaced arrays using general nonlinear minimax optimization method", IEEE Trans., AP-24, pp.501-506, July 1976

[4] J. Wu and A.G. Roederer, "The maximin optimization method for contoured-beam satellite antennas", ESA Journal, Vol.12, No.2, 1988

[5] J. Wu, "Maximin excitation coefficients optimization for array pattern synthesis", Report, No.R417, EMI, Technical University of Denmark, Feb. 1990

[6] P.E. Frandsen and K. Madsen, "Large scale non-gradient minimax optimization", Report No.NI-88-06, Technical University of Denmark 